Review Article

\title{
Fungal Dimorphism and Virulence: Molecular Mechanisms for Temperature Adaptation, Immune Evasion, and In Vivo Survival
}

\author{
Gregory M. Gauthier \\ Department of Medicine, Division of Infectious Diseases, University of Wisconsin School of Medicine \& Public Health, Madison, WI, \\ USA \\ Correspondence should be addressed to Gregory M. Gauthier; gmg@medicine.wisc.edu
}

Received 18 November 2016; Accepted 12 April 2017; Published 23 May 2017

Academic Editor: Anamélia L. Bocca

Copyright ( 2017 Gregory M. Gauthier. This is an open access article distributed under the Creative Commons Attribution License, which permits unrestricted use, distribution, and reproduction in any medium, provided the original work is properly cited.

\begin{abstract}
The thermally dimorphic fungi are a unique group of fungi within the Ascomycota phylum that respond to shifts in temperature by converting between hyphae $\left(22-25^{\circ} \mathrm{C}\right)$ and yeast $\left(37^{\circ} \mathrm{C}\right)$. This morphologic switch, known as the phase transition, defines the biology and lifestyle of these fungi. The conversion to yeast within healthy and immunocompromised mammalian hosts is essential for virulence. In the yeast phase, the thermally dimorphic fungi upregulate genes involved with subverting host immune defenses. This review highlights the molecular mechanisms governing the phase transition and recent advances in how the phase transition promotes infection.
\end{abstract}

\section{Introduction}

The ability for fungi to switch between different morphologic forms is widespread throughout the fungal kingdom and is a fundamental part of their biology. A small subset of fungi within the Ascomycota phylum is considered dimorphic, which refers to capacity to convert between two specific morphologic forms, yeast and hyphae. These fungi are capable of infecting mammals, plants, and insects, and can be subdivided into thermal and nonthermal dimorphic fungi [1]. Thermally dimorphic fungi infect humans and other mammals such as dogs, cats, armadillos, and rodents (Table 1) [2-8]. The thermally dimorphic fungi are unique among fungal pathogens because they can infect humans with normal and impaired immune defenses. This includes the etiologic agents for blastomycosis, histoplasmosis, coccidioidomycosis, paracoccidioidomycosis, and sporotrichosis. In contrast, penicilliosis and emmonsiosis occur in persons with long-standing HIV infection that has progressed to AIDS $\left(\mathrm{CD}^{+} \mathrm{T}\right.$ lymphocytes $\leq 200$ cells $\left./ \mathrm{mm}^{3}\right)$ or have impaired cell-mediated immunity for other reasons (e.g., solid organ transplant) [9-11]. Nonthermal dimorphic fungi can also cause human infection (e.g., Malassezia furfur) [12] but are more typically phytopathogenic or entomopathogenic. For example, Ophiostoma novo-ulmi, the etiologic agent of Dutch elm disease, has destroyed millions of elm trees in Europe and United States [13]. The "zombie ant" fungus, Ophiocordyceps unilateralis, secretes metabolites to alter the behavior of infected ants [14]. This review will focus on how the morphologic switch between hyphae and yeast contributes to virulence with an emphasis on thermally dimorphic fungi relevant to human health.

\section{The Phase Transition}

The reversible morphologic transition between hyphae and yeast, which is known as the phase transition, is fundamental feature of the biology and lifestyle of the dimorphic fungi [1]. In the soil $\left(22-25^{\circ} \mathrm{C}\right)$, these fungi grow as septate hyphae that produce conidia. Disruption of soil by human activities such as construction or natural disasters can aerosolize conidia and hyphal fragments. When inhaled into the warm lungs of a mammalian host $\left(37^{\circ} \mathrm{C}\right)$, these infectious propagules convert into pathogenic yeast (or spherules for Coccidioides) to cause pneumonia [1]. Once infection is established in the 
TABLE 1: Thermally dimorphic fungi pathogenic to humans and mammals.

\begin{tabular}{lc}
\hline Fungus & Clinical Disease \\
\hline Blastomyces dermatitidis and gilchristii & Blastomycosis \\
Histoplasma capsulatum & Histoplasmosis \\
Coccidioides immitis and posadasii & Coccidioidomycosis \\
Paracoccidioides brasiliensis and lutzii & Paracoccidioidomycosis \\
Sporothrix schenckii & Sporotrichosis \\
Talaromyces marneffei & Penicilliosis \\
Emmonsia spp. & Emmonsiosis \\
Lacazia loboi & Lacaziosis \\
\hline
\end{tabular}

lungs, the yeast (or spherules) can disseminate to other organs such as the skin, bone, or brain.

Although temperature is the predominate stimulus that influences the phase transition-hyphae at $22-25^{\circ} \mathrm{C}$ and yeast at $37^{\circ} \mathrm{C}$, additional stimuli that impact the dimorphic switch include carbon dioxide $\left(\mathrm{CO}_{2}\right)$ tension, exogenous cysteine, and estradiol. Elevated $\mathrm{CO}_{2}$ tension $\left(5 \% \mathrm{CO}_{2}\right)$ is required for the arthroconidia of Coccidioides spp. to germinate into spherules at $37^{\circ} \mathrm{C}$ and for optional growth of Histoplasma capsulatum yeast $[15,16]$. In the human lung, $\mathrm{CO}_{2}$ tension is approximately 150 -fold higher than ambient air, which provides an optimal amount of $\mathrm{CO}_{2}$ for phase transition [17]. In response to an upshift in temperature, mitochondrial respiration ceases in Histoplasma, Blastomyces, and Paracoccidioides [18, 19]. To reactivate respiration and complete the morphologic switch to yeast, the uptake of exogenous cysteine is required $[18,19]$. The production of $17 \beta$-estradiol by humans influences the morphologic shift and growth of Coccidioides and Paracoccidioides, which in turn, modulates the severity of infection in women. In the presence of $17 \beta$-estradiol, the growth of Coccidioides spherules at $37^{\circ} \mathrm{C}$ is accelerated, which may explain the increased risk for disseminated coccidioidomycosis in pregnant women [20, 21]. Moreover, in vitro analysis has demonstrated that Coccidioides spherules exhibit saturable binding of $17 \beta$-estradiol [21]. In contrast to Coccidioides, the morphologic switch from hyphae or conidia to yeast in Paracoccidioides is blocked by $17 \beta$-estradiol [22, 23]. In a murine model of pulmonary infection, the conversion of conidia to yeast is impaired in female, but not in male mice [24]. In humans, the incidence of paracoccidioidomycosis is 11-30-fold higher in adult males than in adult females despite similar frequency of Paracoccidioides exposure. Prior to puberty, the male-to-female ratio is $1: 1$ [25].

These observations have prompted investigation to the mechanisms by which estradiol and gender influence fungal development and the host response. Gene expression microarray analysis of $P$. brasiliensis strain $\mathrm{Pb} 01$ demonstrated that impaired conversion to yeast at $37^{\circ} \mathrm{C}$ in the presence of $17 \beta$ estradiol reduced the transcription of genes involved with cell signaling (small GTPase RhoA, palmitoyltransferase), heat shock (HSP40, HSP70, and HSP90), chitin synthesis (chitin synthase), and glucan remodeling ( $\beta$-1,3-glucan synthase, $\alpha$-1,3-glucan synthase) [25]. When stimulated with paracoccin, a lectin-binding protein with chitinase activity, female mice exhibit a stronger Th1 cytokine response with increased production of tumor necrosis factor alpha (TNF- $\alpha$ ), interferon gamma (INF- $\gamma$ ), and interleukin 12 (IL-12), along with increased macrophage fungicidal activity when compared to male mice [26]. Following oophorectomy and treatment with testosterone, the cytokine response shifted from Th1 to Th2 in female mice. Castration of male mice coupled with estradiol therapy favored a Th1 cytokine response instead of a Th2 cytokine response [26]. Collectively, these findings highlight the importance of sex steroid hormones and gender on fungal development and host susceptibility.

\section{Yeast-Phase Virulence Factors and Subversion of Host Immune Defenses}

Once inhaled into the lungs, conidia are ingested by macrophages, where they germinate into yeast (or spherules for Coccidioides) and replicate. Histoplasma capsulatum, Coccidioides immitis and posadasii, Sporothrix schenckii, Paracoccidioides brasiliensis and lutzii, and Talaromyces marneffei replicate inside and outside of innate immune cells [27-31]. Traditionally, Blastomyces spp. were thought to be exclusively extracellular; however, recent research demonstrates that $B$. dermatitidis conidia ingested by macrophages survive and convert to yeast [32].

During the phase transition, the thermally dimorphic fungi upregulate yeast-phase specific genes including Blastomyces adhesion-1 (BAD-1), calcium-binding protein-1 (CBP1), yeast-phase specific-3 (YPS3), and spherule outer wall glycoprotein (SOWgp) to actively subvert host immune defenses. B. dermatitidis and B. gilchristii express BAD1 (formerly WI-1), a $120 \mathrm{kDA}$ secreted, multifunctional protein serves as an adhesion and immune evasin [33-38]. Secreted BAD1 binds back to the yeast cell surface via interactions with chitin and also remains soluble in the extracellular milieu [33-35]. Cell surface-bound BAD1 binds yeast to host cells via complement receptors (CR3, CD14) and heparan sulfate to promote yeast cell adhesion to host cells. BAD-1 bound to the yeast cell surface inhibits production of TNF- $\alpha$ by macrophages and neutrophils in a transforming growth factor- $\beta$ (TGF- $\beta$ ) dependent manner [33, 36-38]. In contrast, soluble BAD- 1 blocks TNF- $\alpha$ production independent of TGF- $\beta$ [36]. TNF- $\alpha$ is a critical cytokine for proper host defense against the dimorphic fungi. Neutralization of TNF- $\alpha$ in a murine model of infection results in progressive pulmonary blastomycosis [37]. Moreover, in 2008, the Food and Drug Administration (FDA) issued a warning of increased risk for histoplasmosis, blastomycosis, and coccidioidomycosis for persons on TNF- $\alpha$ inhibitors for treatment of autoimmune disorders (e.g., rheumatoid arthritis and Crohn's disease) [39]. In addition to affecting TNF- $\alpha$ production, BAD1 also impairs the adaptive immune response by inhibiting the activation of CD4+ T lymphocytes, which decreases IL-17 and INF- $\gamma$ production [33]. The adhesion and immunomodulatory activities of BAD1 are essential for Blastomyces pathogenesis. Deletion of BAD1 renders Blastomyces yeast avirulent in murine model of pulmonary infection [40]. In addition to BAD1, Blastomyces dermatitidis 
secretes a dipeptidyl-peptidase IVA (DppIVA) to modulate host immunity. DppIV is a serine protease that cleaves GM-CSF, a potent cytokine that activates macrophages and neutrophils to kill fungi [41]. Silencing DppIVA by RNA interference (RNAi) reduces survival of $B$. dermatitidis yeast cocultured with GM-CSF-activated macrophages and neutrophils [41]. Moreover, DppIVA-RNAi strains have attenuated virulence during pulmonary infection [41]. In contrast to $B$. dermatitidis, $H$. capsulatum DppIVA is not detected extracellularly and does not contribute to virulence $[42,43]$.

Analogous to BAD1, Coccidioides SOWgp is localized to the spherule cell surface and an important virulence factor. SOWgp facilitates binding of spherules to host extracellular matrix (ECM) proteins including laminin, fibronectin, and collagen [44]. Deletion of SOWgp (SOWgp $\Delta)$ in Coccidioides impairs spherule adherence to ECM proteins and results in attenuated virulence in a murine model of pulmonary infection [44].

In $H$. capsulatum, $C B P 1$ is a secreted virulence factor that promotes intracellular replication of yeast $[45,46]$. CBP1 binds calcium, exists as homodimer, is resistant to protease degradation, and is structurally related to a group of membrane lipid-binding proteins known as saposins [47, 48]. CBP1 secreted by intracellular $H$. capsulatum yeast induces macrophage apoptosis and lysis by inducing transcription of host cell caspases, transcription factors (NUPR1/p8, TRB3), and genes involved with endoplasmic reticulum (ER) stress [46]. Thus, macrophage lysis is an active process directed by the fungus and not due to high intracellular fungal burden. Similar to $B A D 1, C B P 1$ is an essential virulence factor. $C B P 1$ null mutants $(C B P 1 \triangle)$ are unable to induce macrophage apoptosis and are avirulent in murine model of pulmonary infection $[45,46]$. In addition to $C B P 1, H$. capsulatum secretes YPS3, which binds back to chitin in the yeast cell wall and facilitates extrapulmonary dissemination to the liver and spleen [49].

During the morphologic switch from hyphae to yeast or conidia to yeast, dimorphic fungi undergo extensive remodeling of the cell wall including glucan composition. Reorganization of glucan content has the potential to impede recognition of pathogen-associated molecular patterns (PAMPs) by host immune cells. During the morphologic switch, the amount of $\beta$-(1,3)-glucan in the cell wall of Blastomyces and Paracoccidioides declines from $\approx 40 \%$ in hyphae to $\approx 5 \%$ in yeast $[50,51]$. The reduction of $\beta$ $(1,3)$-glucan in the yeast cell wall may limit its recognition by dectin- 1 on innate immune cells and mannose-binding lectins $[17,52]$. In contrast, $H$. capsulatum does not reduce $\beta$-(1,3)-glucan in yeast cells, but rather it uses $\alpha$ $(1,3)$-glucan as a "shield" to block dectin-1 recognition of $\beta$-(1,3)-glucan [53]. Thus, the dimorphic fungi utilize multiple strategies including secreted virulence factors and modification of the yeast cell wall to subvert host immune defenses to establish infection including in persons with intact immune systems.

The ability of thermally dimorphic fungi to subvert host immune defenses is not $100 \%$ effective. The host can mount an immune response to halt the progression of infection.
Epidemiologic studies have demonstrated that $\approx 50 \%$ of persons exposed to Blastomyces spp. develop symptomatic infection, whereas $\approx 50 \%$ have asymptomatic or subclinical infection [54, 55]. Similarly, inhalation of Histoplasma capsulatum, Coccidioides spp., and Paracoccidioides spp. results in symptomatic infection in $<10 \%, 33-50 \%$, and $<5 \%$ of healthy persons, respectively [56-58]. Intact innate and adaptive immune defenses along with the ability to "wall-off" yeast in granulomas are critical for host defense against infection. Following the conversion of conidia to yeast, dendritic cells and macrophages interact with and engulf yeast cells. Gene expression analysis of dendritic cells that have phagocytozed $P$. brasiliensis yeast demonstrated upregulation of transcripts involved with generating a protective immune response including TNF- $\alpha$, IL-12, and chemokines (CCL22, CCL27, and CXCL10) [59]. In addition, the dectin-1 receptor was upregulated, which induces phagocytosis, generation of reactive oxygen species, and proinflammatory cytokines and chemokines in response to binding $\beta$-(1,3)-glucan $[59,60]$. Chemokines promote leukocyte migration to sites of infection [59]. Similarly, macrophages infected with $P$. brasiliensis also induce a proinflammatory response with upregulation of TNF- $\alpha$, chemokines (CCL21, CCL22, CXCL4, CXC11, and CXCL14), and kinases (IRAK2) [61]. These findings highlight the ability of the immune defenses to limit the impact of fungal virulence factors.

\section{Regulation of the Phase Transition}

The transition from hyphae or conidia to yeast at $37^{\circ} \mathrm{C}$ is essential for virulence. The discovery of a hybrid histidine kinase encoded by DRK1 in Blastomyces and Histoplasma provided the first genetic proof that the morphologic switch to yeast is directly linked to virulence [62]. DRK1 null $(D R K 1 \Delta)$, insertional mutants, and RNA interference(RNAi-) silenced strains grow as hyphae at $37^{\circ} \mathrm{C}$ instead of yeast, fail to upregulate yeast-phase specific virulence factors such as $B A D 1$ and $C B P 1$, and are avirulent in a murine model of infection [62]. The function of DRK1 is conserved among the thermally dimorphic fungi. In T. marneffei, DRKA (a DRK1 homolog) is critical for the conversion of conidia to yeast in macrophages [63]. In Sporothrix, Paracoccidioides, and T. marneffei, the transcript abundance of $D R K 1$ is higher in yeast $\left(37^{\circ} \mathrm{C}\right)$ than in hyphae $\left(25^{\circ} \mathrm{C}\right)$ [63-65]. DRK1 is predicted to function as part of the high-osmolarity glycerol (HOG) signaling cascade, which facilitates adaptation to osmotic, oxidative, and temperature stresses [17]. Accordingly, DRK1 transcription is also upregulated in response to osmotic stress in Paracoccidioides and T. marneffei $[63,65]$. In addition to facilitating adaptation to temperature and osmotic stress, DRK1 also influences the integrity of the cell wall $[62,63]$.

Regulation of the morphologic shift is complex and not limited to DRK1. The transcription factors encoded by RYP1-4 (required for yeast phase) also govern the phase transition and regulate a set of yeast-phase specific genes involved in virulence at $37^{\circ} \mathrm{C}$. These transcription factors are upregulated at $37^{\circ} \mathrm{C}$ and are conserved among dimorphic and filamentous fungi [66-68]. RYP1 is a homolog of the 
master regulator WOR1 in C. albicans, whereas RYP2 and RYP3 are part of the velvet complex, VosA and VelB, respectively. $R Y P 4$ is a $\mathrm{Zn}(\mathrm{II})_{2} \mathrm{Cys}_{6}$ zinc binuclear cluster domain protein that is homologous to A. nidulans FacB; however, it does not appear to be involved acetate utilization [68]. These transcription factors form an integrated network in which they directly bind and regulate a common set of core genes including those important for virulence such as $C B P 1$ and YPS3 [68]. Silencing RYP1-4 transcription results in cells that fail to properly undergo the phase transition and grow as hyphae at $37^{\circ} \mathrm{C}$ [66-68].

The morphologic switch in the opposite direction, yeast to hyphae, is also important for pathogenesis. Growth as hyphae promotes survival in the environment, generation of conidia to facilitate transmission to new hosts, and genetic diversity through mating [1]. B. dermatitidis SREB and $H$. capsulatum SRE1 encode a GATA transcription factor that governs the transition to hyphae following a drop in temperature from $37^{\circ} \mathrm{C}$ to $22-25^{\circ} \mathrm{C}$ [69-71]. SREB null mutants (SREBA) and SRE1-RNAi strains fail to complete the conversion to hyphae [69-71]. The role of this GATA transcription factor on temperature adaptation is conserved in other fungi. A homolog of SREB and SRE1 in C. neoformans, CIR1, is essential for thermotolerance at $37^{\circ} \mathrm{C}$ [72]. In $B$. dermatitidis, the defect in the morphologic switch corresponds to a decrease in the biosynthesis of neutral lipids (ergosterol, triacylglycerol) and lipid droplets [70]. Supplementation with exogenous saturated fatty acids (palmitic acid, 16:0, and stearic acid, 18:0) partially corrected the defects in morphogenesis and lipid droplet formation [70]. This suggests that neutral lipid metabolism has to potentially influence the phase transition to hyphae at ambient temperature. SREB and SRE1 also act as negative regulators of genes involved with siderophore biosynthesis and iron uptake; however, this role appears to be independent of the phase transition $[69,70]$. In H. capsulatum, deletion of VMA1, which encodes a vacuolar ATPase involved with intracellular iron homeostasis, results in cells that fail to convert to hyphae at $25^{\circ} \mathrm{C}$. This indicates the potential for iron metabolism not regulated by $S R E B$ to affect the temperature-dependent morphologic switch [73]. In T. marneffei, conversion to hyphae and maintenance of filamentous morphology at $25^{\circ} \mathrm{C}$ is governed by transcription factors encoded by HGRA and TUPA, respectively $[74,75]$. In addition to transcriptional regulators, $\mathrm{N}$-acetylglucosamine (GlcNAc) accelerates the conversion from yeast to hyphae in $B$. dermatitidis and H. capsulatum via NGT1 and NGT2 transmembrane transporters [76].

\section{In Vivo Transcriptional Profiling}

The use of forward genetic strategies such as insertional mutagenesis has substantively advanced the field of medical mycology as related to the thermally dimorphic fungi. This has led to the discovery of novel genes and gene networks that regulate the phase transition (e.g., DRK1, RYP1-3, and $S R E B)$. In the age of genome-wide association studies, an untapped reservoir for uncovering novel genes or gene networks in the dimorphic fungi is transcriptional profiling of yeast during infection. To identify genes important for pathogenicity, in vivo transcription profiling was performed for Blastomyces dermatitidis strain 26199 using a murine model of pulmonary infection [77, 78]. A novel, 2-step technique was developed to efficiently separate $B$. dermatitidis yeast from murine lung tissue to obtain high-quality RNA for RNA-sequencing (RNA-Seq) [77]. To identify $B$. dermatitidis genes with altered transcription independent of temperature or other conditions, the transcriptional profile of yeast isolated from mouse lungs was compared to yeast cocultured with macrophages at $37^{\circ} \mathrm{C}$, yeast grown in vitro without bone marrow-derived macrophages at $37^{\circ} \mathrm{C}$, and hyphae at $22^{\circ} \mathrm{C}$ using $\mathrm{K}$-means cluster analysis [78]. This analysis identified 72 genes that were upregulated in vivo $>2$-fold and independent of temperature, macrophage cocultivation, and media conditions. A subset of these genes included those that encode proteins secreted into the extracellular milieu, metal cation uptake and transport, and amino acid metabolism [78].

Genes involved with zinc acquisition are upregulated by $B$. dermatitidis yeast during pulmonary infection. This includes a zincophore (PRA1/ZPS1), high-affinity zinc transporter (ZRT1), and low affinity zinc transporter (ZRT2) [78]. In Candida albicans, PRA1 is secreted in the extracellular environment to bind zinc and deliver it to the fungus via its interaction with ZRT1 at the cell surface [79]. In C. albicans, Aspergillus fumigatus, and Ustilago maydis, PRA1 and ZRT are coregulated and syntenic. Although PRA1 and ZRT1 appear to be coregulated in Blastomyces, these genes are not syntenic. Surprisingly, PRA1 is not well conserved among the dimorphic fungi and is absent in the genomes of $H$. capsulatum, Paracoccidioides spp., and Emmonsia; however, homologs are present in Coccidioides. In C. albicans, PRA1 is postulated to impact pathogenesis. Deletion of PRA1 results in mutants that have reduced ability to lyse endothelial cells under zinc-deplete conditions [79]. The impact of PRA1 during in vivo infection has not yet been investigated.

In addition to upregulating zinc-scavenging mechanisms in vivo, $B$. dermatitidis increases the transcription of NIC1, which encodes a nickel transporter [78]. Nickel is required for the proper function of urease, an enzyme that catalyzes the conversion of urea to ammonia and $\mathrm{CO}_{2}$. Urea is found in mammalian tissues as a product of purine nucleotide catabolism [80]. In Coccidioides, urease is released from spherules during replication and damages tissue through production of ammonia, which alkalinizes the microenvironment [81]. Deletion of the urease gene (UREA) in C. posadasii results in attenuated virulence in murine model of pulmonary infection. At sites of pulmonary infection, UREA cells are unable to catabolize urea in lung tissue and fail to lower the $\mathrm{pH}$ (tissue $\mathrm{pH} 7.2$ for UREA versus $\mathrm{pH} 7.7$ for wild type). Moreover, mice infected with the null mutant exhibited a more organized immune response with well-formed granulomas encasing UREA cells [81]. In Cryptococcus neoformans, NIC1 and URE1 contribute to invasion of the brain. Deletion of either gene results in decreased ability for NIC1 $\triangle$ and URE1 $1 \triangle$ yeast cells to penetrate the central nervous system [82]. URE1 also contributes to the pathogenesis of Cryptococcus gattii, which primarily causes pulmonary infection 
without an increased predilection for CNS invasion in animal models [83, 84]. C. gattii URE1S have attenuated virulence during pulmonary infection, reduced capacity to disseminate to the bloodstream, and impaired intracellular replication within macrophages [83].

During pulmonary infection, $B$. dermatitidis upregulates dioxygenases involved in the catabolism of amino acids [78]. This includes 4-hydroxyphenylpyruvate dioxygenase (4-HPPD, $H p d A)$, homogentisate 1,2-dioxygenase (HmgA), indoleamine 2,3-dioxygenase (IDO), and cysteine dioxygenase $(C D G)$. $H p d A$ and $H m g A$ are conserved among the dimorphic fungi and are localized on a gene cluster [85]. Although the precise role for $H p d A$ and $H m g A$ is not known in $B$. dermatitidis, research on T. marneffei has illuminated how these genes involved with tyrosine catabolism influence pathogenesis. $H p d A$ and $H m g A$ null mutants are hypersensitive to oxidative stress and have impaired spore germination to yeast in murine and human macrophages [85]. Inhibition of 4-HPPD activity appears to be important for the temperature-dependent morphologic shift. Chemical inhibition of 4-HPPD by NTBC (2-(2-nitro-4-trifluoromethylbenzoyl)-cyclohexane-1, 3-dione) in T. marneffei and $P$. brasiliensis blocks the conversion of conidia or hyphae to yeast following an increase in temperature from $25^{\circ} \mathrm{C}$ to $37^{\circ} \mathrm{C}[85,86]$.

The role of fungal IDO on tryptophan degradation is poorly understood; however, tumor cells upregulate IDO to degrade tryptophan in the microenvironment to evade host immune cells [87]. Pulmonary infection with $H$. capsulatum and $P$. brasiliensis induces host IDO, which reduces fungal growth, inhibits Th17 T lymphocyte differentiation, and limits excessive tissue inflammation [88, 89].

In addition to cysteine dioxygenase $(C D G), B$. dermatitidis upregulates cysteine synthase A (CSA) and a sulfite efflux pump (SSU1) during pulmonary infection [78]. CSA encodes an enzyme involved with the biosynthesis of L-cysteine from acetyl-L-serine. CDG breaks down L-cysteine to L-cysteine sulfonic acid which can be further catabolized to pyruvate and sulfite. The accumulation sulfite is potentially toxic to cells and is secreted via an efflux pump encoded by SSU1. In C. albicans, deletion of CDG1 and SSU1 impairs hyphal development in the presence of cysteine and $C D G 1 \Delta$, but not $S S U 1 \Delta$, and attenuates virulence during murine infection [90]. In dermatophytes such as Arthroderma benhamiae, the catabolism of cysteine to sulfite by CDO1 followed by efflux of sulfite into the extracellular environment by SSU1 is postulated to promote breakdown of keratin to facilitate fungal growth [91]. A. benhamiae CDO1 and SSU1 null mutants have impaired ability to grow on keratin-rich substrates such as hair and nails [91]. On the basis of these data, there is potential that the breakdown of cysteine and sulfite secretion could promote the growth of Blastomyces yeast in skin, which is abundant in keratin and the most common site for extrapulmonary dissemination.

\section{Conclusions}

The thermally dimorphic fungi are a unique group of ascomycetes that are capable of infecting persons with intact and impaired immune defenses. Their ability to adapt to core body temperature $\left(37^{\circ} \mathrm{C}\right)$ and transition to yeast morphology is essential for virulence. The morphologic switch to yeast is associated with the upregulation of specific virulence factors that promote adhesion to host tissues, growth in and lysis of macrophages, blunt proper cytokine responses, and impair cell-mediated immunity. The regulation of the reversible transition between hyphae and yeast requires these fungi to adapt and respond to numerous stimuli including temperature, $\mathrm{CO}_{2}$ tension, and sex hormones. In vivo transcriptional profiling has begun to uncover previously unrecognized genes important for propagation and virulence in the mammalian host.

\section{Conflicts of Interest}

The author declares that he has no conflicts of interest.

\section{References}

[1] G. M. Gauthier, "Dimorphism in fungal pathogens of mammals, plants, and insects," PLoS Pathogens, vol. 11, no. 12, article e1004608, 2015.

[2] G. A. Sarosi, M. R. Eckman, S. F. Davies, and W. K. Laskey, "Canine blastomycosis as a harbinger of human disease," Annals of Internal Medicine, vol. 91, no. 5, pp. 733-755, 1979.

[3] J. L. Anderson, J. L. Dieckman, K. D. Reed, and J. K. Meece, "Canine blastomycosis in Wisconsin: a survey of smallanimal veterinary practices," Medical Mycology, vol. 52, no. 7, pp. 774-779, 2014.

[4] C. Brömel and J. E. Sykes, "Histoplasmosis in dogs and cats," Clinical Techniques in Small Animal Practice, vol. 20, no. 4, pp. 227-232, 2005

[5] A. Graupmann-Kuzma, B. A. Valentine, L. F. Shubitz, S. M. Dial, B. Watrous, and S. J. Tornquist, "Coccidioidomycosis in dogs and cats: a review," Journal of the American Animal Hospital Association, vol. 44, no. 5, pp. 226-235, 2008.

[6] R. S. Reis, R. Almeida-Paes, M. Mde Muniz et al., "Molecular characterization of Sporothrix schenckii isolates from humans and cats involved in the sporotrichosis epidemic in Rio de Janeiro, Brazil," Memórias do Instituto Oswaldo Cruz vol. 104, no. 5, pp. 769-774, 2009.

[7] T. D. Arantes, R. C. Theodoro, M. Mde Teixeria, M. Sde Bosco, and E. Bagagli, "Environmental mapping of Paracoccidioides spp. in Brazil reveals new clues into genetic diversity, biogeography and wild host association," PLoS Neglected Tropical Diseases, vol. 10, no. 4, article e0004606, 2016.

[8] C. Cao, L. Liang, W. Wang et al., "Common reservoirs for Penicillium marneffei infection in humans and rodents, China," Emerging Infectious Diseases, vol. 17, no. 2, pp. 209214, 2011.

[9] C. Kenyon, K. Boorchis, C. Corcoran et al., "A dimorphic fungus causing disseminated infection in South Africa," New England Journal of Medicine, vol. 369, no. 15, pp. 14161424, 2013.

[10] I. S. Schwartz, N. P. Govender, C. Corcoran et al., "Clinical characteristics, diagnosis, management, and outcomes of disseminated emmonsiosis: a retrospective case series," Clinical Infectious Diseases, vol. 61, no. 6, pp. 1004-1012, 2015.

[11] T. Le, M. Wolbers, N. H. Chi et al., "Epidemiology, seasonality, and predictors of outcome of AIDS-associated Penicillium 
marneffei infection in Ho Chi Minh City, Viet Nam," Clinical Infectious Diseases, vol. 52, no. 7, pp. 945-952, 2011.

[12] S. Youngchim, J. D. Nosanchuk, S. Pornsuwan, S. Kajiwara, and N. Vanittanakom, "The role of L-DOPA on melanization and mycelial production in Malassezia furfur," PLoS One, vol. 8, no. 6, article e63764, 2013.

[13] M. Nigg, J. Laroche, C. R. Landry, and L. Bernier, "RNAseq analysis highlights specific transcriptome signatures of yeast and mycelial growth phases of Dutch elm disease fungus Ophiostoma novo-ulmi," G3, vol. 5, no. 11, pp. 24872495, 2015.

[14] H. C. Evans, S. L. Elliot, and D. P. Hughes, "Ophiocordyceps unilateralis: a keystone species for unraveling ecosystem functioning and biodiversity of fungi in tropical forests?" Communicative \& Integrative Biology, vol. 4, no. 5, pp. 598602, 2011.

[15] S. A. Klotz, D. J. Drutz, M. Huppert, S. H. Sun, and P. L. DeMarsh, "The critical role of $\mathrm{CO}_{2}$ in the morphogenesis of Coccidioides immitis in cell-free subcutaneous chambers," Journal of Infectious Diseases, vol. 150, no. 1, pp. 127-134, 1984.

[16] L. Pine, "Studies on the growth of Histoplasma capsulatum. I. Growth of the yeast phase in liquid media," Journal of Bacteriology, vol. 68, no. 6, pp. 671-679, 1954.

[17] G. M. Gauthier and B. S. Klein, "Insights into fungal morphogenesis and immune evasion: fungal conidia, when situated in mammalian lungs, may switch from mold to pathogenic yeasts or spore-forming spherules," Microbe, vol. 3, no. 8, pp. 416-423, 2008.

[18] B. Maresca, A. M. Lambowitz, V. B. Kumar, G. A. Grant, G. S. Kobayashi, and G. Medof, "Role of cysteine in regulating morphogenesis and mitochondrial activity in the dimorphic fungus Histoplasma capsulatum," Proceeding of the National Academy of Sciences, USA, vol. 78, no. 7, pp. 4596-4600, 1981.

[19] G. Medoff, A. Painter, and G. S. Kobayashi, "Mycelial-toyeast-phase transitions of the dimorphic fungi Blastomyces dermatitidis and Paracoccidioides brasiliensis," Journal of Bacteriology, vol. 169, no. 9, pp. 4055-4060, 1987.

[20] D. J. Drutz, M. Huppert, S. H. Sun, and W. L. McGuire, "Human sex hormones stimulate the growth and maturation of Coccidioides immitis," Infection and Immunity, vol. 32, no. 2, pp. 897-907, 1981.

[21] B. L. Powell, D. J. Drutz, M. Huppert, and S. H. Sun, "Relationship of progesterone- and estradiol-binding proteins in Coccidioides immitis to coccidioidal dissemination in pregnancy," Infection and Immunity, vol. 40, no. 2, pp. 478-485, 1983.

[22] A. Restrepo, M. E. Salazar, L. E. Cano, E. P. Stover, D. Feldman, and D. A. Stevens, "Estrogens inhibit mycelium-to-yeast transformation in the fungus Paracoccidioides brasiliensis: implications for resistance of females to paracoccidioidomycosis," Infection and Immunity, vol. 46, no. 2, pp. 346-353, 1984.

[23] M. E. Salazar, A. Restrepo, and D. A. Stevens, "Inhibition by estrogens of conidium-to-yeast conversion in the fungus Paracoccidioides brasiliensis," Infection and Immunity, vol. 56, no. 3, pp. 711-713, 1988.

[24] B. H. Aristizábal, K. V. Clemons, A. M. Cock, A. Restrepo, and D. A. Stevens, "Experimental Paracoccidioides brasiliensis infection in mice: influence of the hormonal status of the host on tissue responses," Medical Mycology, vol. 40, no. 2, pp. 169-178, 2002.
[25] J. Shankar, T. D. Wu, K. V. Clemons, J. P. Monteiro, L. F. Mirels, and D. A. Stevens, "Influence of $17 \beta$-estradiol on gene expression of Paracoccidioides during mycelia-to-yeast transition," PLoS One, vol. 6, no. 12, article e28402, 2011.

[26] C. F. Pinzan, L. P. Ruas, A. S. Casabona-Fortunato, F. C. Carvalho, and M.-C. Roque-Barreira, "Immunologic basis for the gender differences in murine Paracoccidioides brasiliensis infection," PLoS One, vol. 5, no. 5, article e10757, 2010.

[27] D. O. Inglis, M. Voorhies, D. R. Hocking Murray, and A. Sil, "Comparative transcriptomics of infectious spores from the fungal pathogen Histoplasma capsulatum reveals a core set of transcripts that specify infectious and pathogenic states," Eukaryotic Cell, vol. 12, no. 6, pp. 828-852, 2013.

[28] L. Beaman, E. Benjamini, and D. Pappagianis, "Role of lymphocytes in macrophage-induced killing of Coccidioides immitis in vitro," Infection and Immunity, vol. 34, no. 2, pp. 347-353, 1981

[29] P. Mdel Jiménez, A. Restrepo, D. Radzioch, L. E. Cano, and L. F. Garcia, "Importance of complement 3 and mannose receptors in phagocytosis of Paracoccidioides brasiliensis conidia by Nramp1 congenic macrophage cell lines," FEMS Immunology and Medical Microbiology, vol. 47, no. 1, pp. 56-66, 2006.

[30] S. Guzman-Beltran, A. Perez-Torres, C. Coronel-Cruz, and H. Torres-Guerrero, "Phagocytic receptors on macrophages distinguish between different Sporothrix schenckii morphotypes," Microbes and Infection, vol. 14, no. 12, pp. 1093-1101, 2012.

[31] K. J. Boyce and A. Andrianopoulos, "Morphogenetic circuity regulating growth and development in the dimorphic pathogen Penicillium marneffei," Eukaryotic Cell, vol. 12, no. 2, pp. 154-160, 2013.

[32] A. K. Sterkel, R. Mettelman, M. Wüthrich, and B. S. Klein, "The unappreciated intracellular lifestyle of Blastomyces dermatitidis," Journal of Immunology, vol. 914, no. 4, pp. 1796-1805, 2015.

[33] T. T. Brandhorst, R. Roy, M. Wüthrich et al., "Structure and function of a fungal adhesion that binds heparin and mimics thrombospondin-1 by blocking $\mathrm{T}$ cell activation and effector function," PLoS Pathogens, vol. 9, no. 7, article e1003464, 2013.

[34] A. Beaussart, T. Brandhorst, Y. F. Dufrêne, and B. S. Klein, "Blastomyces virulence adhesion-1 protein binding to glycosaminoglycans is enhanced by protein disulfide isomerase," MBio, vol. 6, no. 5, pp. e014303-e014315, 2015.

[35] T. Brandhorst, M. Wüthrich, B. Finkel-Jimenez, and B. S. Klein, "A C-terminal EGF-like domain governs BAD1 localization to the yeast cell surface and fungal adherence to phagocytes, but is dispensable in immune modulation and pathogenicity of Blastomyces dermatitidis," Molecular Microbiology, vol. 48, no. 1, pp. 53-65, 2003.

[36] B. Finkel-Jimenez, M. Wüthrich, and B. S. Klein, "BAD1, an essential virulence factor of Blastomyces dermatitidis, suppresses host TNF-alpha production through TGF-betadependent and -independent mechanisms," Journal of Immunology, vol. 168, no. 11, pp. 5746-5755, 2002.

[37] B. Finkel-Jimenez, M. Wüthrich, T. T. Brandhorst, and B. S. Klein, "The WI-1 adhesin blocks phagocyte TNF-alpha production, imparting pathogenicity on Blastomyces dermatitidis," Journal of Immunology, vol. 166, no. 4, pp. 2665-2673, 2001.

[38] T. T. Brandhorst, M. Wüthrich, B. Finkel-Jimenez, T. Warner, and B. S. Klein, "Exploiting type 3 complement receptor for TNF-alpha suppression, immune evasion, and progressive 
pulmonary infection," Journal of Immunology, vol. 173, no. 12, pp. 7444-7453, 2004.

[39] FDA Alert, Tumor Necrosis Factor-Alpha Blockers (TNF Blockers), Cimzia (Certolizumab Pegol), Enbrel (Etanercept), Humira (Adalimumab), and Remicade (Infliximab), 2008.

[40] T. T. Brandhorst, M. Wüthrich, T. Warner, and B. S. Klein, "Targeted gene disruption reveals an adhesion indispensable for pathogenicity of Blastomyces dermatitidis," Journal of Experimental Medicine, vol. 189, no. 8, pp. 1207-1216, 1999.

[41] A. K. Sterkel, J. L. Lorenzini, J. S. Fites et al., "Fungal mimicry of a mammalian aminopeptidase disables innate immunity and promotes pathogenicity," Cell Host and Microbe, vol. 19, no. 3, pp. 361-374, 2016.

[42] K. G. Cooper, R. Zarnowski, and J. P. Woods, "Histoplasma capsulatum encodes a dipeptidyl peptidase active against the mammalian immunoregulatory peptide, substance P," PLoS One, vol. 4, no. 4, article e5281, 2009.

[43] K. G. Cooper and J. P. Woods, "Secreted dipeptidyl peptidase IV activity in the dimorphic fungal pathogen Histoplasma capsulatum," Infection and Immunity, vol. 77, no. 6, pp. 2447-2454, 2009.

[44] C. Y. Hung, J. J. Yu, K. R. Seshan, U. Reichard, and G. T. Cole, "A parasite phase-specific adhesion of Coccidioides immitis contributes to the virulence of this respiratory fungal pathogen," Infection and Immunity, vol. 70, no. 7, pp. 34433456, 2002.

[45] T. S. Sebghati, J. T. Engle, and W. E. Goldman, "Intracellular parasitism by Histoplasma capsulatum: fungal virulence and calcium dependence," Science, vol. 290, no. 4595, pp. 13681372, 2000.

[46] D. T. Isaac, C. A. Berkes, B. C. English et al., "Macrophage cell death and transcriptional response are actively triggered by the fungal virulence factor $\mathrm{Cbp} 1$ during $H$. capsulatum infection," Molecular Microbiology, vol. 98, no. 5, pp. 910-929, 2015.

[47] M. R. Beck, G. T. DeKoster, D. M. Hambly, M. L. Gross, D. P. Cistola, and W. E. Goldman, "Structural features responsible for the biological stability of Histoplasma's virulence factor CBP," Biochemistry, vol. 47, no. 15, pp. 4427-4438, 2008.

[48] M. R. Beck, G. T. DeKoster, D. P. Cistola, and W. E. Goldman, "NMR structure of fungal virulence factor reveals structural homology with mammalian saposin," Molecular Microbiology, vol. 72 no. 2, pp. 344-353, 2009.

[49] M. L. Bohse and J. P. Woods, "RNA interference-mediated silencing of the YPS3 gene of Histoplasma capsulatum reveals virulence defects," Infection and Immunity, vol. 75, no. 6, pp. 2811-2817, 2007.

[50] F. Kanetsuna and L. M. Carbonell, "Cell wall composition of the yeastlike and mycelial forms of Blastomyces dermatitidis," Journal of Bacteriology, vol. 106, no. 3, pp. 946-948, 1971.

[51] F. Kanetsuna, L. M. Carbonell, R. E. Moreno, and J. Rodriguez, "Cell wall composition of the yeast and mycelial forms of Paracoccidioides brasiliensis," Journal of Bacteriology, vol. 97, no. 3, pp. 1036-1041, 1969.

[52] A. Koneti, M. J. Linke, E. Brummer, and D. A. Stevens, "Evasion of innate immune responses: evidence for mannose binding lectin inhibition of tumor necrosis factor alpha production by macrophages in response to Blastomyces dermatitidis," Infection and Immunity, vol. 76, no. 3, pp. 994-1002, 2008.

[53] C. A. Rappleye, L. G. Eissenberg, and W. E. Goldman, "Histoplasma capsulatum alpha-(1,3)-glucan blocks innate immune recognition by the beta-glucan receptor," Proceedings of the National Academy of Sciences, USA, vol. 104, no. 4, pp. 1366-1370, 2007.

[54] B. S. Klein, J. M. Vergeront, R. J. Weeks et al., "Isolation of Blastomyces dermatitidis from soil associated with a large outbreak of blastomycosis in Wisconsin," New England Journal of Medicine, vol. 314, no. 9, pp. 529-534, 1986.

[55] B. S. Klein, J. M. Vergeront, A. F. DiSalvo, L. Kaufman, and J. P. Davis, "Two outbreaks of blastomycosis along rivers in Wisconsin. Isolation of Blastomyces dermatitidis from riverbank soil and evidence of its transmission along waterways," American Review of Respiratory Diseases, vol. 136, no. 6, pp. 1333-1338, 1987.

[56] G. S. Deepe, "Chapter 265-“Histoplasma capsulatum (histoplasmosis)"," in Mandell, Douglas, and Bennett's Principles and Practice of Infectious Diseases, J. E. Bennett, R. Dolin and M. J. Blaser, Eds., pp. 2949-2962, Elsevier Saunders, Philadelphia, PA, USA, 2015.

[57] J. N. Galgiani, "Chapter 267-“Coccidioidomycosis (Coccidioides species)"," in Mandell, Douglas, and Bennett's Principles and Practice of Infectious Diseases, J. E. Bennett, R. Dolin and M. J. Blaser, Eds., pp. 2974-2984, Elsevier Saunders, Philadelphia, PA, USA, 2015.

[58] J. A. Parente, C. L. Borges, and M. Pereira, "Paracoccidioides mechanisms of pathogenesis and virulence," in Human Pathogenic Fungi Molecular Biology and Pathogenic Mechanisms, D. J. Sullivan and G. P. Moran, Eds., pp. 317-338, Caister Academic Press, Norfolk, UK, 2014.

[59] A. H. Tavares, L. S. Derengowski, K. S. Ferreira et al., "Murine dendritic cells transcriptional modulation upon Paracoccidioides brasiliensis infection," PLoS Neglected Tropical Diseases, vol. 6, no. 1, article e1459, 2012.

[60] R. A. Drummond and G. D. Brown, "The role of Dectin-1 in the host defense against fungal infections," Current Opinion in Microbiology vol. 14, no. 4, pp. 392-399, 2011.

[61] S. S. Silva, A. H. F. P. Tavares, D. G. Passos-Silva et al., "Transcriptional response of murine macrophages upon infection with opsonized Paracoccidioides brasiliensis yeast cells," Microbes and Infection, vol. 10, no. 1, pp. 12-20, 2008.

[62] J. C. Nemecek, M. Wüthrich, and B. S. Klein, "Global control of dimorphism and virulence in fungi," Science, vol. 312, no. 5773, pp. 583-588, 2016.

[63] K. J. Boyce, L. Schreider, L. Kirszenblat, and A. Andrianopoulos, "The two-component histidine kinases DrkA and SlnA are required for in vivo growth in the human pathogen Penicillium marneffei," Molecular Microbiology, vol. 82, no. 5, pp. 11641184, 2011.

[64] B. Hou, Z. Zhang, F. Zheng, and X. Liu, "Molecular cloning, characterization, and differential expression of DRK1 in Sporothrix schenckii," International Journal of Molecular Medicine, vol. 31, no. 1, pp. 99-104, 2013.

[65] A. F. Chaves, M. V. Navarro, D. G. Castilho, J. C. Calado, P. M. Conceição, and W. L. Batista, "A conserved dimorphismregulating histidine kinase controls the dimorphic switching in Paracoccidioides brasiliensis," FEMS Yeast Research, vol. 16, no. 5, article fow047, 2016.

[66] N. Q. Nguyen and A. Sil, "Temperature-induced switch to the pathogenic yeast form of Histoplasma capsulatum requires Ryp1, a conserved transcriptional regulator," Proceeding of the National Academy of Sciences, USA, vol. 105, no. 12, pp. 4880-4885, 2008. 
[67] R. H. Webster and A. Sil, "Conserved factors Ryp2 and Ryp3 control cell morphology and infectious spore formation in the fungal pathogen Histoplasma capsulatum," Proceeding of the National Academy of Sciences, USA, vol. 105, no. 39, pp. 14573-14578, 2008.

[68] S. Beyham, M. Gutierrez, M. Voorhies, and A. Sil, "A temperature-responsive network links cell shape and virulence traits in a primary fungal pathogen," PLoS Biology, vol. 11, no. 7, article e1001614, 2013.

[69] G. M. Gauthier, T. D. Sullivan, S. S. Gallardo et al., "SREB, a GATA transcription factor that directs disparate fates in Blastomyces dermatitidis including morphogenesis and siderophore biosynthesis," PLoS Pathogens, vol. 6, no. 4, article e1000846, 2010.

[70] A. J. Marty, A. T. Broman, R. Zarnowski et al., "Fungal morphology, iron homeostasis, and lipid metabolism regulated by a GATA transcription factor in Blastomyces dermatitidis," PLoS Pathogens, vol. 11, no. 6, article e1004959, 2015.

[71] L. H. Hwang, E. Seth, S. A. Gilmore, and A. Sil, "SRE1 regulates iron-dependent and -independent pathways in the fungal pathogen Histoplasma capsulatum," Eukaryotic Cell, vol. 11, no. 1, pp. 16-25, 2012.

[72] W. H. Jung, A. Sham, R. White, and J. W. Kronstad, "Iron regulation of the major virulence factors in the AIDSassociated pathogen Cryptococcus neoformans," PLoS Biology, vol. 4, no. 12, article e410, 2006.

[73] J. Hilty, A. G. Smulian, and S. L. Newman, "The Histoplasma capsulatum vacuolar ATPase is required for iron homeostasis, intracellular replication in macrophages, and virulence in a murine model of histoplasmosis," Molecular Microbiology, vol. 70, no. 1, pp. 127-139, 2008.

[74] H. E. Bugeja, M. J. Hynes, and A. Andrianopoulos, "HgrA is necessary and sufficient to drive hyphal growth in the dimorphic pathogen Penicillium marneffei," Molecular Microbiology, vol. 88, no. 5, pp. 998-1014, 2013.

[75] R. B. Todd, J. R. Greenhalgh, M. J. Hynes, and A. Adrianopoulos, "TupA, the Penicillium marneffei Tup1p homologue, represses both yeast and spore development," Molecular Microbiology, vol. 48, no. 1, pp. 85-94, 2003.

[76] S. A. Gilmore, S. Naseem, J. B. Konopka, and A. Sil, "Nacetylglucosamine (GlcNAc) triggers a rapid, temperatureresponsive morphogenetic program in thermally dimorphic fungi," PLoS Genetics, vol. 9, no. 9, article e1003799, 2013.

[77] A. J. Marty, M. Wüthrich, J. C. Carmen et al., "Isolation of Blastomyces dermatitidis yeast from lung tissue during murine infection for in vivo transcriptional profiling," Fungal Genetics and Biology, vol. 56, pp. 1-8, 2013.

[78] J. F. Muñoz, G. M. Gauthier, C. A. Desjardins et al., "The dynamic genome and transcriptome of the human fungal pathogen Blastomyces and close relative Emmonsia," PLoS Genetics, vol. 11, no. 10, article e1005493, 2015.

[79] F. Citiulo, I. D. Jacobsen, P. Miramón et al., "Candida albicans scavenges host zinc via Pral during endothelial invasion," PLoS Pathogens, vol. 8, no. 6, article e1002777, 2012.

[80] H. Z. Wise, C. Y. Hung, E. Whiston, J. W. Taylor, and G. T. Cole, "Extracellular ammonia at sites of pulmonary infection with Coccidioides posadasii contributes to severity of the respiratory disease," Microbial Pathogenesis, vol. 59, no. 60, pp. 19-28, 2013.

[81] F. Mirbod-Donovan, R. Schaller, C. Y. Hung, J. Xue, U. Reichard, and G. T. Cole, "Urease produced by Coccidioides posadasii contributes to the virulence of this respiratory pathogen," Infection and Immunity, vol. 74, no. 1, pp. 504515, 2006.

[82] A. Singh, R. J. Panting, A. Varma et al., "Factors required for activation of urease as a virulence determinant in Cryptococcus neoformans," MBio, vol. 7, no. 3, pp. e00220-e00213, 2013.

[83] V. Feder, L. Kmetzsch, C. C. Staats et al., "Cryptococcus gattii urease as a virulence factor and the relevance of enzymatic activity in cryptococcosis pathogenesis," The FEBS Journal, vol. 282, no. 8, pp. 1406-1418, 2015.

[84] S. C. Chen, W. Meyer, and T. C. Sorrell, "Cryptococcus gattii infections," Clinical Microbiology Reviews, vol. 4, no. 27, pp. 980-1024, 2014.

[85] K. J. Boyce, A. McLauchlan, L. Schreider, and A. Andrianopoulos, "Intracellular growth is dependent on tyrosine catabolism in the dimorphic fungal pathogen Penicillium marneffei," PLoS Pathogens, vol. 11, no. 3, article e1004790, 2015.

[86] L. R. Nunes, R. Costa de Oliveira, and D.B. Leite DB, et al., "Transcriptome analysis of Paracoccidioides brasiliensis cells undergoing mycelium-to-yeast transition," Eukaryotic Cell, vol. 4, no. 11, pp. 2115-2128, 2005.

[87] C. Uyttenhove, L. Pilotte, I. Théate et al., "Evidence for a tumoral immune resistance mechanism based on tryptophan degradation by indoleamine 2,3-dioxygenase," Nature Medicine, vol. 9, no. 10, pp. 1269-1274, 2003.

[88] C. A. Hage, D. J. Horan, M. Durkin et al., "Histoplasma capsulatum preferentially induces IDO in the lung," Medical Mycology, vol. 51, no. 3, pp. 270-279, 2013.

[89] E. F. Araújo, F. V. Loures, S. B. Bazan et al., "Indoleamine 2,3-dioxygenase controls fungal loads and immunity in Paracoccidioidomycosis but is more important to susceptible than resistant hosts," PLoS Neglected Tropical Diseases, vol. 8, no. 11, article e3330, 2014.

[90] F. Hennicke, M. Grumbt, U. Lermann et al., "Factors supporting cysteine tolerance and sulfite production in Candida albicans," Eukaryotic Cell, vol. 12, no. 4, pp. 604-613, 2013.

[91] M. Grumbt, M. Monod, T. Yamada, C. Hertweck, J. Kunert, and P. Staib, "Keratin degradation by dermatophytes relies on cysteine dioxygenase and a sulfite efflux pump," Journal of Investigative Dermatology, vol. 133, no. 6, pp. 1550-1555, 2013. 


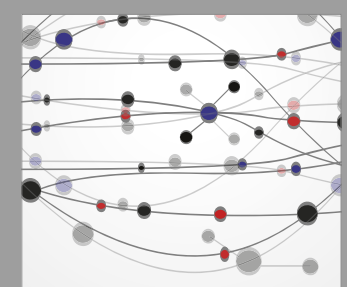

The Scientific World Journal
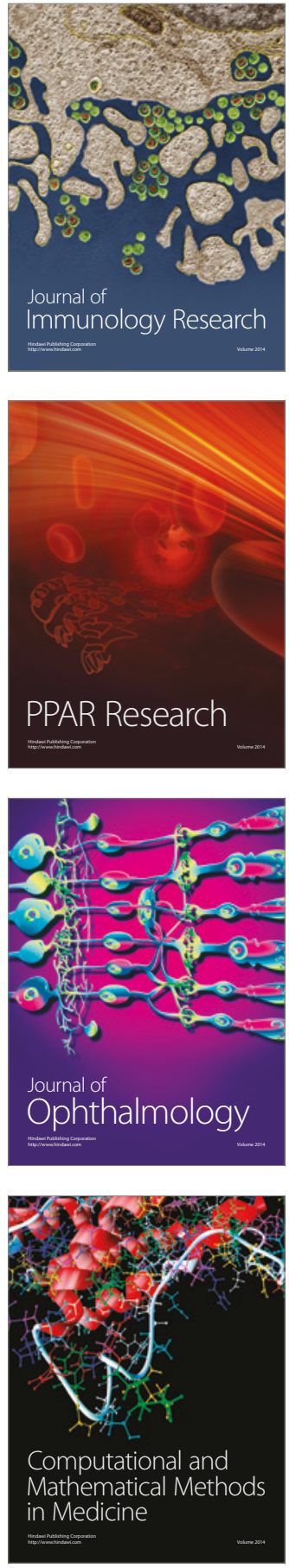

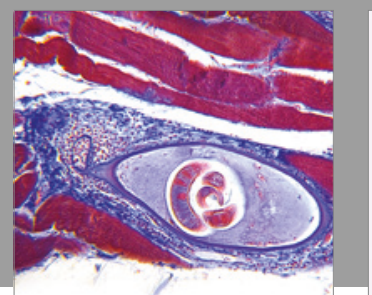

Gastroenterology Research and Practice
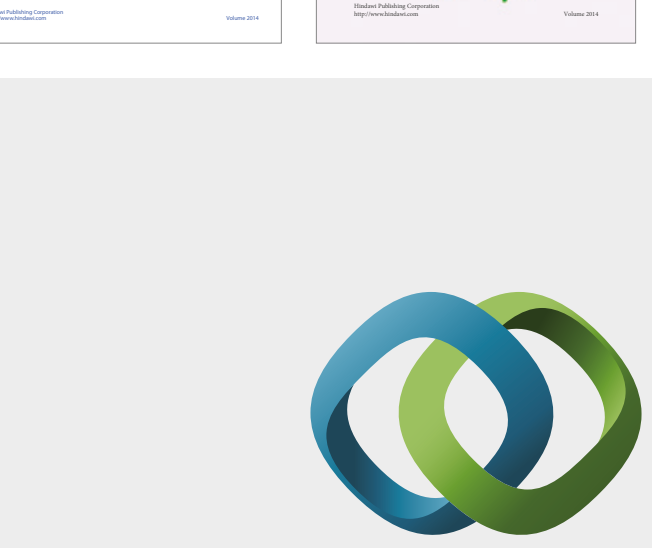

\section{Hindawi}

Submit your manuscripts at

https://www.hindawi.com
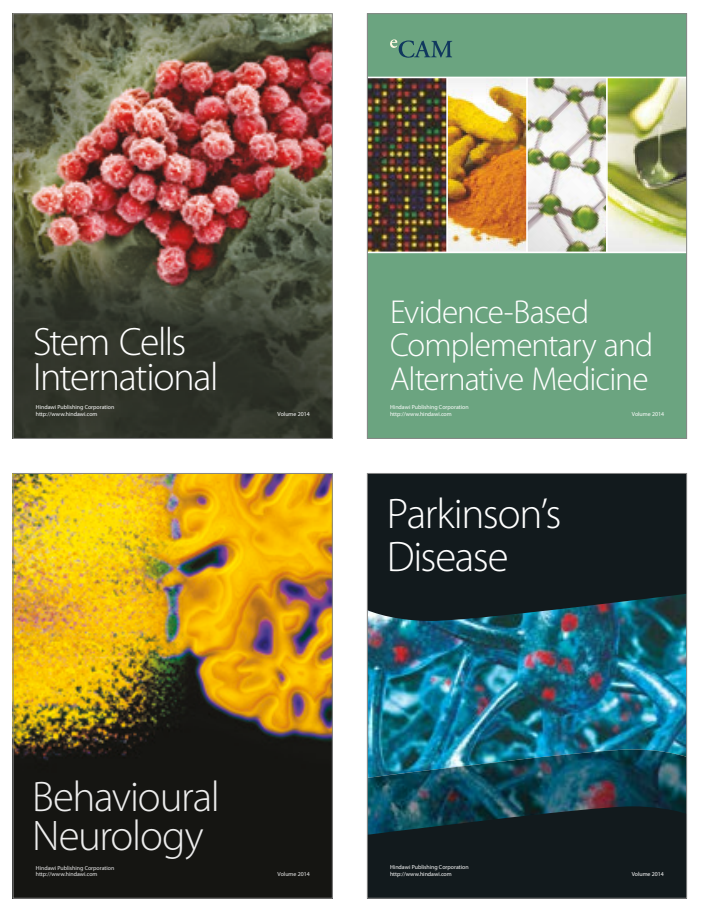
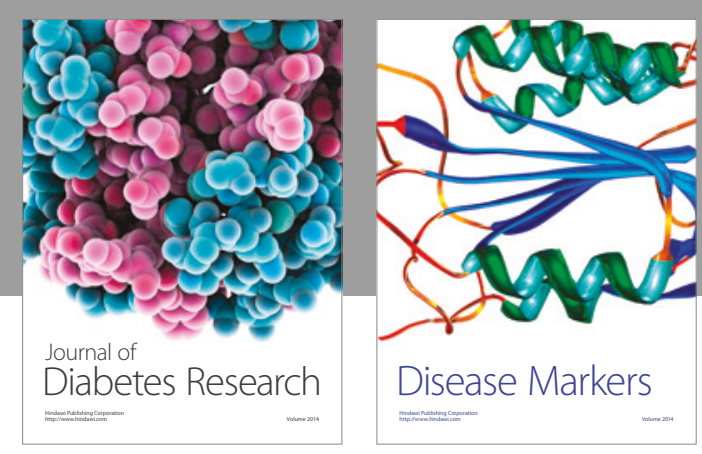

Disease Markers
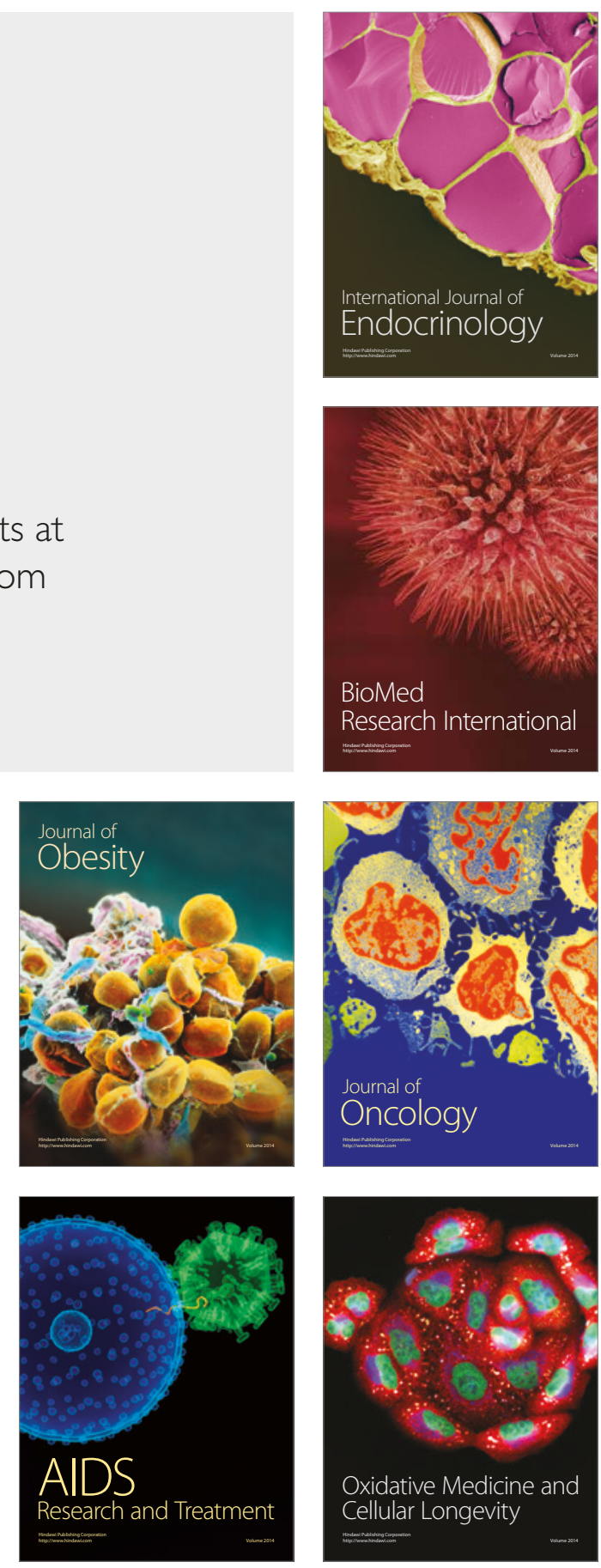